\title{
Commentary: Building bridges, not walls
}

\author{
Anthony L. Estrera, MD
}

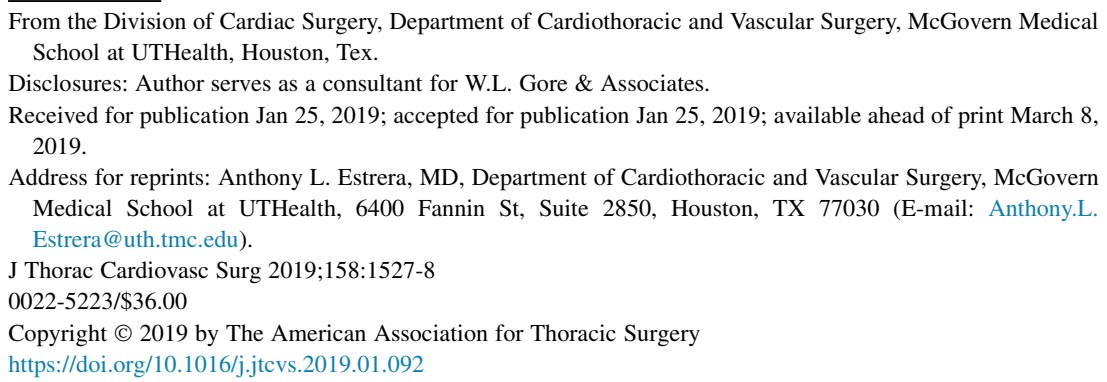

\section{Let's build bridges, not walls.}

- Martin Luther King, Jr (1929-1968)

http://www.blackhistory.org/2018/06/popular-quotes-

from-martin-luther-king-i-have-a-dream-speech.html

Acute type A aortic dissection (ATAAD) is a devastating condition that, when associated with mesenteric malperfusion, may carry an early mortality exceeding $60 \%{ }^{1}$ Although malperfusion may affect any vascular bed during the acute aortic dissection, prognosis depends on the location and duration of the ischemic injury. Mesenteric malperfusion remains a significant challenge, because early identification is difficult, and when the diagnosis is confirmed, it is often too late. Mesenteric malperfusion may present early, with nonspecific symptoms-abdominal pain, nausea, vomiting - and occur intermittently, or even resolve at presentation. Persistent mesenteric malperfusion will lead to severe organ dysfunction, termed malperfusion syndrome, and eventual ischemic necrosis. The challenge is how to identify malperfusion syndrome earlier, so that an intervention can restore flow and prevent irreversible damage.

In this issue of the Journal, Leshnower and colleagues report their experience with their thoracic endovascular aortic repair first approach for patients presenting with ATAAD with mesenteric malperfusion syndrome. ${ }^{2}$ The premise of expeditious reperfusion of the mesenteric vascular bed and delayed proximal aortic repair is not novel, having been adopted by the Michigan group with the use of endovascular aortic fenestration and target vessel stenting. ${ }^{3}$

Leshnower and colleagues ${ }^{2}$ performed a retrospective analysis of the Emory experience with 618 repaired ATAADs and identified 34 (5.5\%) patients who presented with mesenteric malperfusion. The definition used for mesenteric malperfusion was a combination of clinical, chemical, and radiographic parameters, and it appears reasonable in view of the difficulties in confirming this diagnosis in general. The type of intervention (and associated mortality) evolved during the course of the study, starting with proximal repair with exploratory laparotomy

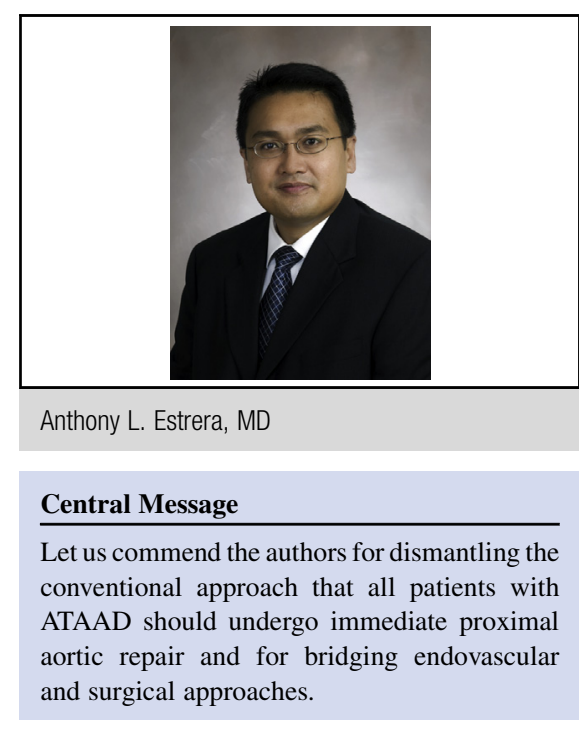

See Article page 1516.

(mortality, 69\%), initial axillobifemoral bypass immediately followed by proximal aortic repair (mortality, $0 \%$ ), proximal aortic repair with antegrade TEVAR (mortality, $80 \%$ ), and initial TEVAR of descending thoracic aorta with delayed proximal aortic repair (mortality 30\%). With the TEVAR first approach, Leshnower and colleagues ${ }^{2}$ clarified that 3 patients died before proximal aortic repair, including 1 death from aortic rupture on post-TEVAR day 6. Considering the TEVAR first strategy as an intention to treat, the early mortality was $46 \%(6 / 13)$, which was not significantly better than any of the other approaches. Similar to the Michigan group, the Emory group has now adopted a treatment algorithm, which aims to correct the mesenteric malperfusion syndrome first, followed by delayed proximal aortic repair. Table 1 highlights similarities and differences between the Emory and Michigan experiences., ${ }^{2,3}$

As has been recognized by most, mesenteric malperfusion syndrome portends a dismal prognosis when associated with ATAAD. Like the Michigan group, the Emory group had evolved their strategy during the study period, because no good approach had yielded acceptable results up to this point. The data presented in the current study of Leshnower and colleagues ${ }^{2}$ does not prove that the TEVAR first approach is better than the other strategies used. It may, however, prevent a subset of patients who have irreversible mesenteric malperfusion syndrome from undergoing a futile proximal aortic repair. The concept espoused by the Emory Group as a bridge to decision may thus be valid. 
TABLE 1. Comparison between the Michigan (fenestration) ${ }^{3}$ and Emory (thoracic endovascular aortic repair first) ${ }^{2}$ strategies to treat acute type A aortic dissection with visceral and mesenteric malperfusion

\begin{tabular}{|c|c|c|}
\hline & University of Michigan* (2008-2017) & Emory (2004-2017) \\
\hline Celiac/mesenteric malperfusion & 35 (135 total malperfusions) & 13 (only mesenteric) \\
\hline Indications & $\begin{array}{l}\text { Hemodynamic stability } \\
\text { No pericardial effusion } \\
\text { No current chest pain } \\
\text { No signs of "rupture" } \\
\text { No severe valve insufficiency }\end{array}$ & $\begin{array}{l}\text { Hemodynamic stability } \\
\text { No pericardial effusion } \\
\text { No current chest pain } \\
\text { No signs of "rupture" }\end{array}$ \\
\hline $\begin{array}{l}\text { Definition of visceral/mesenteric } \\
\text { malperfusion }\end{array}$ & $\begin{array}{l}\text { Combination of physical exam, serum labs (lactate, } \\
\text { pH, LFTs, PT), radiographic evidence } \\
\text { Angiographic: gradient }>15 \mathrm{~mm} \mathrm{Hg}\end{array}$ & $\begin{array}{l}\text { Combination of physical exam, serum labs (lactate, } \\
\text { pH, LFTs, PT), radiographic evidence }\end{array}$ \\
\hline $\begin{array}{l}\text { Associated malperfusion } \\
\text { syndromes }\end{array}$ & Combination (renal, iliac, celiac, mesenteric) $71 \%$ & Renal $(62 \%)$; iliofemoral $(54 \%)$ \\
\hline Endovascular procedure & $\begin{array}{l}\text { Fenestration: ( } 69 \% \text { of total): above celiac for } \\
\text { mesenteric malperfusion; below lowest renal for } \\
\text { iliac malperfusion } \\
\text { Aortic lumen stent ( } 66 \% \text { of total) } \\
\text { Branch stent }(61 \% \text { of total) } \\
\text { Thrombolysis, thrombectomy ( } 13 \% \text { of total) }\end{array}$ & $\begin{array}{l}\text { TEVAR }(\mathrm{n}=10 ; \text { mean coverage, } 211 \mathrm{~mm}) \\
\text { Bare metal stent of visceral segment }(20 \%) \\
\text { Branch stent (renal, SMA, iliac; } 40 \%)\end{array}$ \\
\hline $\begin{array}{l}\text { Confirmation of adequate } \\
\text { mesenteric perfusion }\end{array}$ & $\begin{array}{l}\text { Angiographic with normalization of target vessel } \\
\text { gradient }\end{array}$ & $\begin{array}{l}\text { Angiographic, qualitative, confirmation of femoral } \\
\text { pulses }(100 \%)\end{array}$ \\
\hline Time to proximal repair & $3 \mathrm{~d}(1-6.5 \mathrm{~d})$ & 24 hours after TEVAR \\
\hline \multicolumn{3}{|l|}{ Interval mortality } \\
\hline $\begin{array}{l}\text { Total } \\
\text { Due to aortic rupture }\end{array}$ & $\begin{array}{l}8.8 \%(12 / 135) \\
1.5 \%(2 / 135)\end{array}$ & $\begin{array}{l}23 \%(3 / 13) \\
7.6 \%(1 / 13)\end{array}$ \\
\hline Overall mortality & $29 \%(10 / 35)$ & $46 \%(6 / 13)$ \\
\hline
\end{tabular}

LFTs, Liver function tests; $P T$, prothrombin time; TEVAR, thoracic endovascular aortic repair; SMA, superior mesenteric artery. *Only includes the second decade of the Michigan experience.

The approach of endovascular treatment with delayed proximal aortic repair remains controversial, and certain considerations should be emphasized when considering its application:

1. ATAAD with mesenteric malperfusion syndrome is relatively rare, occurring in about $5 \%$ of all patients.

2. Mesenteric malperfusion should be distinguished from mesenteric malperfusion syndrome, which often implies a significant delay in presentation, leading to end-organ damage. A high index of suspicion is required, and early proximal aortic repair may be adequate if mesenteric malperfusion without end-organ dysfunction is identified early.

3. If an endovascular first approach (whether TEVAR or fenestration) is considered, patients should be in stable condition, without pericardial tamponade, rupture, stroke, coronary ischemia, or severe aortic insufficiency.

4. With adequate anti-impulse therapy, the risk of aortic rupture in the interval period (1-3 days) appears low $(2.2 \% ; 3 / 148$ for both series combined).

5. The required endovascular skill is advancedespecially with aortic fenestrations and target vessel revascularization.
6. The endovascular first approach may provide a "bridge to decision" in cases of true mesenteric malperfusion syndrome, potentially avoiding futile interventions.

In the end, the TEVAR first approach will remain controversial, even as centers' experiences expand. Surgeons from both the Emory and Michigan groups are to be commended for dismantling the conventional approach that all patients with ATAAD—regardless of the presence of mesenteric malperfusion syndrome-should undergo immediate proximal aortic repair and for bridging endovascular and surgical approaches to address this dismal condition.

\section{References}

1. Di Eusanio M, Trimarchi S, Patel HJ, Hutchison S, Suzuki T, Peterson MD, et al. Clinical presentation, management, and short-term outcome of patients with type A acute dissection complicated by mesenteric malperfusion: observations from the International Registry of Acute Aortic Dissection. J Thorac Cardiovasc Surg. 2013;145:385-90.e1.

2. Leshnower BG, Keeling WB, Duwayri YM, Jordan WD Jr, Chen EP. The "thoracic endovascular aortic repair-first" strategy for acute type A dissection with mesenteric malperfusion: initial results compared to conventional algorithms. J Thorac Cardiovasc Surg. 2019;158:1516-24.

3. Yang B, Rosati CM, Norton EL, Kim KM, Khaja MS, Dasika N, et al. Endovascular fenestration/stenting first followed by delayed open aortic repair for acute type A aortic dissection with malperfusion syndrome. Circulation. 2018;138: 2091-103. 